\title{
David Oliver: Targeting long hospital stays
}

\author{
David Oliver consultant in geriatrics and acute general medicine
}

Berkshire

NHS hospitals are consistently running at over $90 \%$ bed occupancy, ${ }^{1}$ compromising patient safety and bed management and leaving no capacity to deal with surges in demand or infection outbreaks.

NHS England estimates that a fifth of hospital beds are used by patients who will spend over three weeks in hospital. ${ }^{2}$ Its chief executive, Simon Stevens, has pledged to reduce these long stays by a quarter. And the NHS plan for 2018-19 includes a commitment to "improve patient flow inside hospitals," focusing specifically on "stranded" and "super stranded" patients who have been in hospital for over seven or 21 days, respectively. ${ }^{34}$

Long stays result from a whole range of factors. These may include avoidable delays in assessment, investigation, treatment, decisions, or referrals to community services or rehabilitation; and patients may remain medically unstable or still require the full facilities of the general hospital. ${ }^{56}$

They may also result from delayed transfers of patients who are medically fit to leave but are waiting to access out-of-hospital care. In 2016-17, bed days from delayed transfers of care hit a record high of 2.25 million. ${ }^{7}$ This was a $25 \%$ increase on the previous year, and the National Audit Office has calculated that the real number of stranded patients is far higher than that officially recorded. ${ }^{8}$

Since that peak, the number of delayed transfers of care has fallen. After a government target for tackling these, and an additional $£ 2$ bn in earmarked social care funding, the overall number fell by $12 \%$ in $2017-18 .{ }^{9}$

\section{NHS England estimates that a fifth of hospital beds are used by patients who will spend over three weeks in hospital}

I worry whether the turnaround we've seen in the past 12 months can be sustained. Step-down care is likely to be even harder to access given the financial challenges in clinical commissioning groups and local authorities, recent reductions in care home places, cuts in provision of social care packages, and worsening access to intermediate care. ${ }^{10-12}$ It's not clear whether those services will be given sufficient priority in the NHS 10 year plan or in local plans for integrated care systems. ${ }^{13}$ And it will be at least two years before the green paper on adult social care becomes a white paper or act of parliament. ${ }^{14}$

Ultimately, I suspect that the solutions lie in joined-up local system leadership and a relentless focus on operational detail and sustainable implementation-a view shared by the King's Fund in last week's report on integrated care. ${ }^{15}$ It remains to be seen whether, after the initial push and focus, such turnarounds can be sustained or whether every health system can replicate these successes. Personally, I doubt that central targets and toolkits can achieve the goal.

We need more capacity in out-of-hospital health and care services and more flexibility for local leaders to collaborate and innovate. For the good of all patients needing scarce acute beds and all of those needlessly trapped in them, let's hope that the plan works.

Competing interests: See www.bmj.com/about-bmj/freelance-contributors/davidoliver.

Provenance and peer review: Commissioned; not externally peer reviewed.

NHS England. Bed availability and occupancy data—overnight. https://www.england.nhs. uk/statistics/statistical-work-areas/bed-availability-and-occupancy/bed-data-overnight/.

2 Baker C, House of Commons Library. Briefing paper no 8210-NHS winter pressures 2017-18, England. 3 April 2018. http://researchbriefings.files.parliament.uk/documents/ CBP-8210/CBP-8210.pdf.

3 NHS England. NHS launches plan to improve patient care by cutting long hospital stays. 13 June 2018. https://www.england.nhs.uk/2018/06/nhs-launches-plan-to-improve-patientcare-by-cutting-long-hospital-stays/.

4 NHS England. NHS Improvement. Refreshing NHS plans for 2018-19. 2 Feb 2018. https: //www.england.nhs.uk/wp-content/uploads/2018/02/planning-guidance-18-19.pdf.

5 NHS Improvement. National priorities for acute hospitals 2017—good practice guide: focus on improving patient flow. July 2017. https://improvement.nhs.uk/documents/1426/ Patient_Flow_Guidance_2017__13_July_2017.pdf.

6 British Geriatrics Society, NHS Benchmarking Network. Managing frailty and delayed transfers of care in the acute setting. 2018. https://bit.ly/2JGUYav.

7 Edge R, NHS Providers. Delayed transfers of care-the story of 2017/18. 24 May 2018. http://nhsproviders.org/news-blogs/blogs/delayed-transfers-of-care-the-story-of-201718.

8 National Audit Office. Department of Health: discharging older patients from hospital. 26 May 2016. https://www.nao.org.uk/wp-content/uploads/2015/12/Discharging-older-patientsfrom-hospital.pdf.

9 Baker C, House of Commons Library. Briefing paper no 7281-NHS Key Statistics: England, May 2018. 21 May 2018. http://researchbriefings.files.parliament.uk/documents/ CBP-7281/CBP-7281.pdf.

10 Ruddick G. Care home closures set to rise as funding crisis bites. Guardian 11 Jan 2017. https://www.theguardian.com/society/2017/jan/11/care-home-closures-funding-crisis.

11 King's Fund. Social care for older people: home truths. 15 Sept 2016. https://www. kingsfund.org.uk/publications/social-care-older-people.

12 NHS Benchmarking Network. National Audit of Intermediate Care: summary report-England. Nov 2017. https://bit.ly/2zhXCek. 
13 King's Fund. The NHS 10-year plan: how should the extra funding be spent? 12 July 2018. https://www.kingsfund.org.uk/publications/nhs-10-year-plan.

14 House of Commons Library. Social care: forthcoming green paper on older people and parallel programme (England). 15 Aug 2018. https://researchbriefings.parliament.uk/ ResearchBriefing/Summary/CBP-8002.
15 King's Fund. A year of integrated care systems: reviewing the journey so far. 20 Sept 2018. https://www.kingsfund.org.uk/publications/year-integrated-care-systems.

Published by the BMJ Publishing Group Limited. For permission to use (where not already granted under a licence) please go to http://group.bmj.com/group/rights-licensing/ permissions 